\title{
Acute pancreatitis in childhood: Research of pathogenesis and clinical implications
}

\author{
ZVI WEIZMAN MD
}

\begin{abstract}
Z WeIzMAn. Acute pancreatitis in childhood: Research of pathogenesis and clinical implications. Can J Gastroenterol $1997 ; 11(3): 249-253$. Acute pancreatitis in children is more common than has previously been considered. A recent literature analysis has demonstrated significant resulting morbidity and mortality. Clinical awareness has improved dramatically, as demonstrated by the increase in the number of recent publications and etiological considerations. This review describes novel considerations in research related to the pathogenesis of acute pancreatitis and the arising clinical implications. This relationship is discussed regarding a better understanding of pathogenesis in pediatric disorders; increasing awareness; preventing damage by drugs and toxins; using novel diagnostic markers; and introducing new therapeutic tools.
\end{abstract}

Key Words: Acute pancreatitis, Childhood, Diagnostic markers, Toxins

\section{Pancréatite aiguë chez l'enfant : recherche sur} sa pathogenèse et ses répercussions cliniques

RÉSUMÉ : La pancréatite aiguë chez les enfants est plus courante qu'on l'avait d'abord cru. Une récente analyse de la littérature a permis de démontrer qu'il en résulte une morbidité et une mortalité importantes. Les cliniciens y sont de plus en plus sensibilisés, comme en font foi l'augmentation du nombre de publications et l'attention que reçoivent les questions d'ordre étiologique. Le but de cette synthèse est de décrire les nouvelles avenues de la recherche sur la pathogenèse de la pancréatite aiguë et sur ses nouvelles implications cliniques. Ce lien sera étudié pour permettre une meilleure compréhension de la pathogenèse des maladies infantiles, pour sensibiliser les lecteurs à l'existence de la maladie, pour promouvoir la prévention au moyen de médicaments et de toxines, et le recours à de nouveaux marqueurs diagnostiques et de nouveaux outils thérapeutiques.
A lthough acute pancreatitis occurs less frequently in children than in adults (unpublished data), it is probably more common in childhood than has previously been considered. Clinical awareness of this illness has improved immensely over recent years.

A retrospective literature analysis of acute pancreatitis has been completed recently in our unit. In this study we analyzed the clinical details of 453 pediatric patients with acute pancreatitis published in English between 1957 and
1995 (unpublished data). Various etiologies of pediatric acute pancreatitis have been described recently in the literature. While only about 16 causes of this illness were described in 1965, nearly 75 etiological considerations were reported in the subsequent years up to 1995. Some of the novel etiologies recently published include human immunodeficiency virus infection (1) and associated drug therapy with dideoxyinosine (2), organic acidemias (3), bone marrow transplantation (4), massive hemolysis (5), mitochondrial encephalomyopa-

This paper was part of a symposium entitled "Selected topics in pediatric gastroenterology and nutrition" held in October 1995 to honour the academic career of Dr Gordon G Forstner

Pediatric Gastroenterology and Nutrition Unit, Soroka Medical Center, Ben-Gurion University of the Negev, Beer-Sheva, Israel

Correspondence: Dr Zvi Weizman, Associate Professor and Head, Pediatric Gastroenterology and Nutrition Unit, Soroka Medical Center, PO Box 151, Beer-Sheva 84101, Israel. Telephone 97-27-640-0310, fax 97-27-640-0028, e-mail wzvi@bgumail.bgu.ac.il 


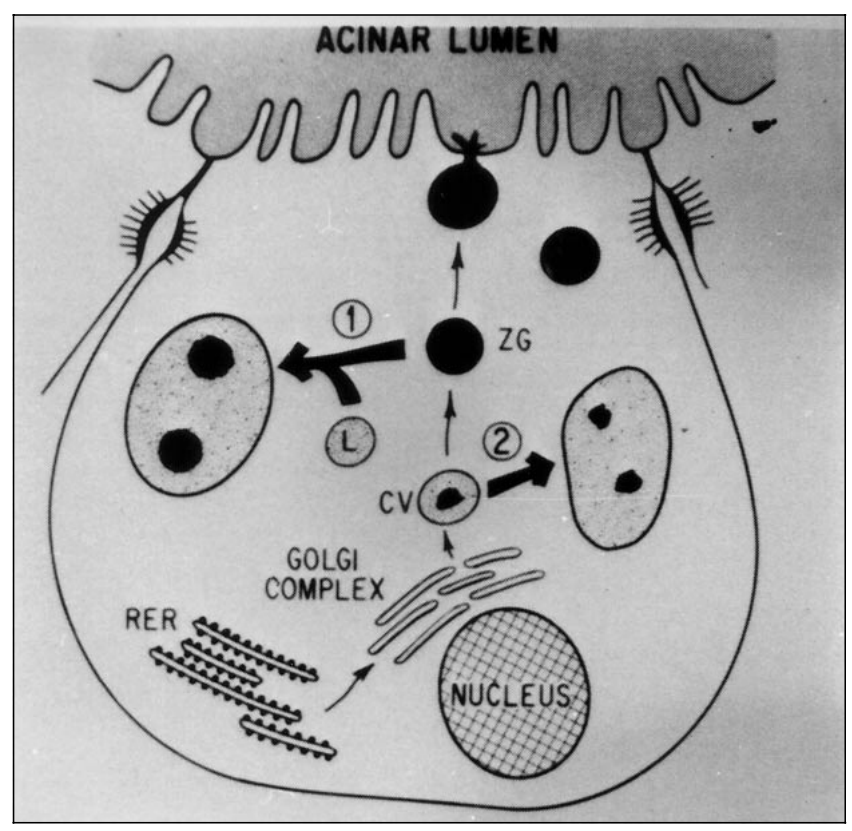

Figure 1) Normal and abnormal routing of lysosomal hydrolases and digestive enzymes within the pancreatic acinar cell. Thin arrows show the physiological pathways that include synthesis of enzymes into the cisterna of the rough-surfaced endoplasmic reticulum (RER), and transport to the Golgi complex and condensing vacuoles $(\mathrm{CV})$. Subsequently there is segregation of lysosomal hydrolases into lysosomes $(L)$ with maturation of CV into zymogen granules (ZG) that contain digestive enzymes, and discharge of these enzymes into the acinar lumen. Abnormal pathways are shown with heavy arrows. Pathway 1 involves fusion of zymogen granules with lysosomes (crinophagy) and is seen in diet-induced pancreatitis. Pathway 2, found in hyperstimulation-induced pancreatitis, involves failure of condensing vacuole maturation to proceed normally and results in formation of large vacuoles that contain both lysosomal hydrolases and digestive enzymes. Reproduced with permission from reference 35

thies (6), and chronic intestinal pseudo-obstruction (7). Similarly, the cumulative number of articles published in the literature has increased from about 25 in 1965 to nearly 250 in 1995.

In our review we also found that acute pancreatitis in children carries significant morbidity and mortality. Thirty per cent of patients required therapy with parenteral alimentation, and in $28 \%$, a surgical procedure was performed. Complications, such as pseudocyst formation (occurring in $12 \%$ ) or recurrence $(8 \%)$, were not rare. In $14 \%$ of cases a fatal outcome was reported. Although this retrospective review presents a selective patient population, these figures demonstrate the serious nature of this illness in pediatrics.

The pancreas of the young individual is probably more vulnerable to the development of acute pancreatitis. A recent animal study performed in our laboratory evaluated experimental cerulein-induced pancreatitis in rats. A comparison between young and adult rats demonstrated a more severe form of pancreatitis in the younger age group. This presented as higher plasma levels of amylase and a significant difference in the extent of pancreatic inflammation (unpublished data).

The aim of the present review was to demonstrate a few novel approaches in the research of acute pancreatitis pathogenesis and its clinical implications. This relationship will be demonstrated and discussed regarding several key points including an understanding of pathogenesis and increased awareness in pediatric disorders; preventing potential damage of drugs or toxins; and the use of novel diagnostic and therapeutic tools.

\section{UNDERSTANDING THE PATHOGENESIS OF ACUTE PANCREATITIS}

During acute pancreatitis activated proteolytic enzymes such as trypsin and elastase are detected within the pancreas and in pancreatic juice. These activated enzymes are thought to play an important initiating role in the development of pancreatic autodigestion and inflammation. The two common causes of pancreatitis in adults are stones in the biliary tract and ethanol ingestion. The pathogenesis of acute pancreatitis in these disorders, however, remains poorly understood, and how these factors lead to intrapancreatic proteolytic enzyme activation remains an enigma. Most speculation has focused on either reflux of duodenal content into the pancreatic duct where enterokinase may activate trypsinogen, or pancreatic ductal hypertension, resulting from an outflow obstruction that leads to extravasation of juices into the gland and subsequent intraparenchymal activation of digestive enzymes. Both possibilities presume that exocrine pancreatic enzyme activation occurs outside the acinar cell. However, unequivocal support for either of these possibilities is not available. In addition, it is not clear from the above pathogenetic mechanisms how acute pancreatitis develops in some pediatric disorders where classical injury mechanisms, such as obstructive biliary diseases, are not relevant. Several recent experimental studies suggest that autoactivation of enzymes occurs within the acinar cell and not in the interstitium, as has been commonly believed (8). In these models, protein synthesis and intracellular transport to the Golgi complex remain normal, but the secretion of digestive enzymes is blocked (Figure 1). Digestive enzymes are present in large vacuoles containing lysosomal hydrolases, such as cathepsin B, that are capable of activating trypsinogen (9). Such an etiological mechanism is more appropriate for understanding how various systemic pediatric disorders may cause pancreatitis. In these illnesses there is no evidence of biliary blockade, intrapancreatic ductal hypertension or bile regurgitation. Future research into the etiology of pancreatic inflammation in appropriate animal models of various pediatric diseases will permit a better understanding of the pathogenesis of this illness in younger patients.

\section{INCREASING AWARENESS}

A great variety of etiologies of acute pancreatitis are now evident in pediatric patients. This process is the result, in part, of an increasing awareness by physicians of this condition. There are several examples to demonstrate how a high index of clinical suspicion in pediatric patients allows one to diagnose this entity more frequently. 
The first example is organophosphates and carbamates, which are used as common domestic and agricultural pesticides and insecticides. Acute pancreatitis has been described in a few adult patients after accidental ingestion of an anticholinesterase insecticide, a substance not previously known to affect the exocrine pancreas (10). The direct toxic effects of these chemicals on the pancreas have been established in a few animal studies (11). In view of these observations Weizman and Sofer (12) noticed that children with this type of intoxication very often develop vomiting and abdominal pain associated with unexplained hyperglycemia. They suspected that this clinical constellation resulted from acute pancreatitis. Subsequently they performed a prospective study in 17 consecutive intoxicated children and demonstrated the development of acute pancreatitis in five (Table 1) (12).

Another example is the acute pancreatitis caused by yellow scorpion envenomation. This association was first described in a few adult reports. An extensive study of several animal species demonstrated very clearly that these venoms are able to induce pancreatic inflammation (13). Subsequently Sofer and colleagues (14) conducted a prospective study and showed that exocrine pancreatic involvement is not rare in children with this form of envenomation, which appears to explain some of the common gastrointestinal symptoms observed in these patients. Furthermore, an in vitro study using rat pancreatic tissue demonstrated that scorpion toxin induces pancreatic hypersecretion indirectly by stimulating the release of acetylcholine from pancreatic nerves (15). These effects were blocked by atropine (Figure 2 ). We speculate, therefore, that atropine may be clinically effective in suppressing certain sequelae of scorpion envenomation in humans. As a result we are currently trying to establish these effects in the experimental animal and, if successful, to investigate further possible therapeutic benefits in affected humans.

\section{PREVENTING DAMAGE OF DRUGS AND TOXINS}

More than 85 drugs have been reported to cause acute pancreatitis (8). The drugs associated with the highest incidence are azathioprine and mercaptopurine ( $3 \%$ to $5 \%$ ), and didanosine (up to $23 \%$ ). However, little is known about the pathogenesis of drug-induced pancreatitis.

Azathioprine-induced pancreatic damage may be treatable and avoidable based upon investigation of its pathogenesis. A number of recent observations have suggested that oxidative stresses, such as hydrogen peroxide or lipid peroxide, can be a major contributor to the cellular injury found in acute pancreatitis (16). Glutathione represents one of the major intracellular defence systems against mediators of oxidative stress (Figure 3). Glutathione has been shown to be protective in experimental pancreatitis (17). Hepatic glutathione depletion occurs in rats treated with azathioprine. Azathioprine may undergo glutathione-mediated metabolism in the pancreas, leading to depletion of pancreatic glutathione (18). Alpha-tocopherol is an effective antioxi-
TABLE 1

Selective clinical and laboratory data in 17 children with anticholinesterase insecticide intoxication

\begin{tabular}{lcccccc}
\hline \# & $\begin{array}{c}\text { Age } \\
\text { (years) }\end{array}$ & Sex & $\begin{array}{c}\text { Gl } \\
\text { symp }\end{array}$ & $\begin{array}{c}\text { Serum } \\
\text { amylase } \\
(\mathbf{U} / \mathbf{L})\end{array}$ & $\begin{array}{c}\text { Serum } \\
\text { trypsin } \\
(\mathbf{n g} / \mathbf{m L})\end{array}$ & $\begin{array}{c}\text { Serum } \\
\text { glucose } \\
(\mathbf{m g} / \mathbf{1 0 0} \mathbf{~ m L})\end{array}$ \\
\hline 1 & 5 & $\mathrm{M}$ & $\mathrm{V}, \mathrm{AP}$ & 360 & 690 & 500 \\
2 & 1.5 & $\mathrm{M}$ & - & 270 & 160 & 243 \\
3 & 1.6 & $\mathrm{M}$ & - & 140 & 210 & 180 \\
4 & 1.7 & $\mathrm{M}$ & $\mathrm{V}, \mathrm{AP}$ & 800 & 1280 & 330 \\
5 & 8 & $\mathrm{M}$ & - & 210 & 190 & 147 \\
6 & 1.6 & $\mathrm{~F}$ & $\mathrm{D}$ & 190 & 160 & 280 \\
7 & 4 & $\mathrm{~F}$ & $\mathrm{~V}, \mathrm{D}$ & 70 & 130 & 214 \\
8 & 3 & $\mathrm{~F}$ & $\mathrm{SAP}$ & 80 & 640 & 355 \\
9 & 1 & $\mathrm{M}$ & $\mathrm{D}$ & 90 & 180 & 115 \\
10 & 1 & $\mathrm{~F}$ & - & 60 & 170 & 132 \\
11 & 2 & $\mathrm{M}$ & - & 260 & 110 & 219 \\
12 & 5 & $\mathrm{~F}$ & $\mathrm{~N}, \mathrm{SAP}$ & 560 & 720 & 365 \\
13 & 8 & $\mathrm{M}$ & $\mathrm{AP}$ & 440 & 1240 & 395 \\
14 & 5 & $\mathrm{M}$ & $\mathrm{N}$ & 80 & 220 & 284 \\
15 & 4 & $\mathrm{~F}$ & $\mathrm{~V}$ & 70 & 140 & 148 \\
16 & 1.3 & $\mathrm{M}$ & $\mathrm{D}$ & 310 & 105 & 142 \\
17 & 1.6 & $\mathrm{~F}$ & $\mathrm{~N}$ & 84 & 144 & 161 \\
\hline
\end{tabular}

AP Abdominal pain; D Diarrhea; F Female; Gl symp Gastrointestinal symptoms, $M$ Male; N Nausea; SAP Severe abdominal pain; $V$ Vomiting. Data from reference 12

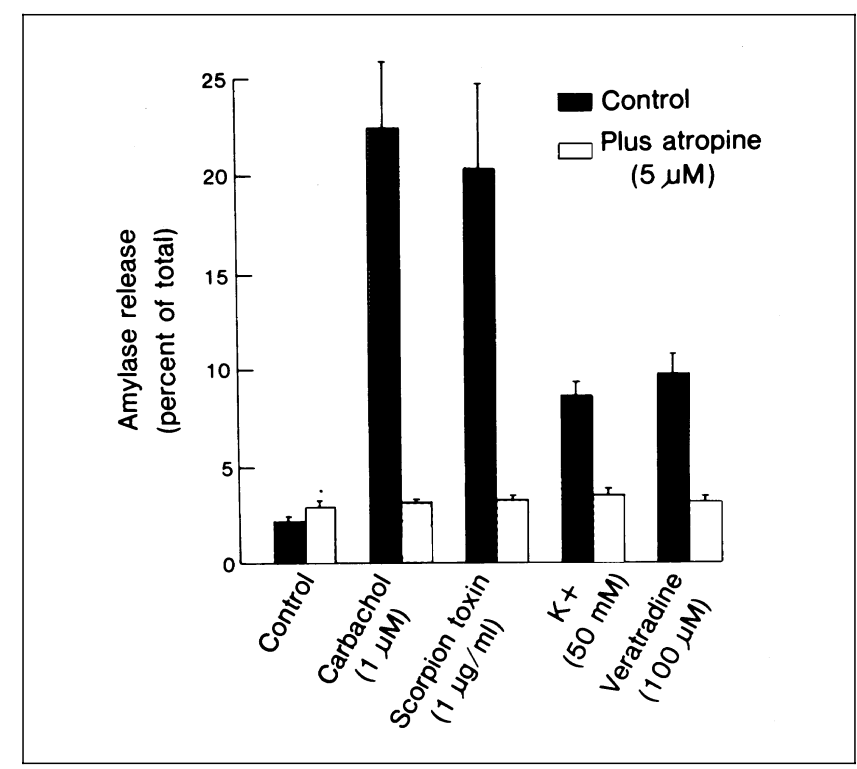

Figure 2) Effect of atropine on control, carbachol-and scorpion toxininduced amylase release from rat pancreatic lobules during a $30 \mathrm{~min}$ incubation. Veratridine (a plant alkaloid) and potassium ions at high concentration are both able to depolarize cells and stimulate amylase release. All effects were blocked by atropine. All values are mean \pm SE of five experiments. Reproduced with permission from reference 15

dant that has been demonstrated to ameliorate the course of experimental pancreatitis (19). This observation suggests a possible beneficial role for antioxidants in azathioprineinduced pancreatitis. This mode of therapy needs to be studied in humans.

Another example is the acute pancreatitis that is a well- 


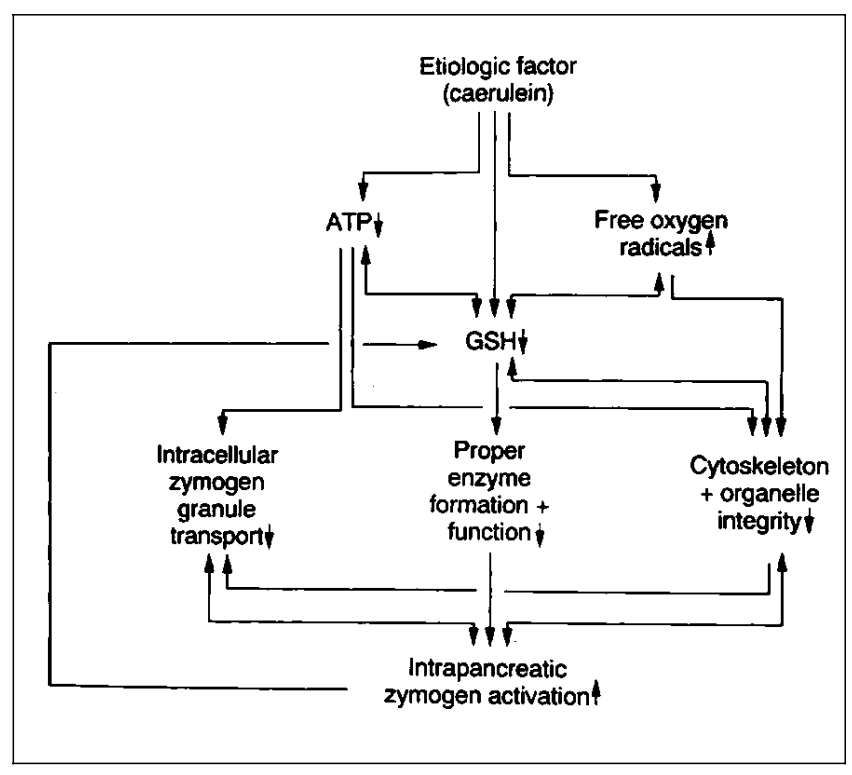

Figure 3) A proposed series of steps by which a reduction in intracellular glutathione (GSH) or in the ratio of reduced:oxidized GSH could either initiate or contribute to the autodigestive process in acute pancreatitis resulting from premature zymogen activation. ATP Adenosine triphosphate. Reproduced with permission from reference 36

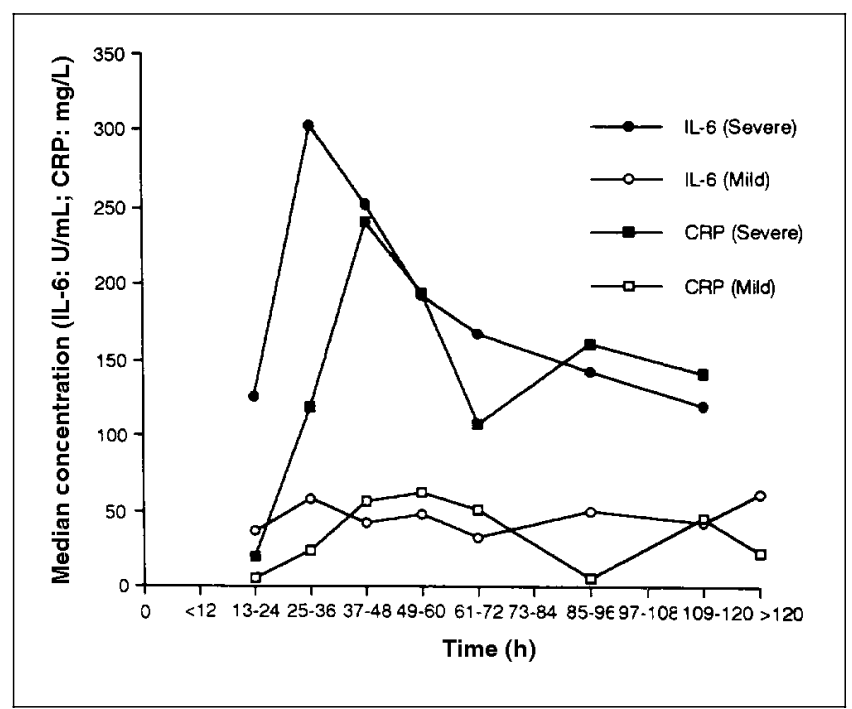

Figure 4) Median concentration of interleukin (IL)- 6 and C reactive protein (CRP) throughout a five-day study in 10 patients with severe and 14 with mild acute pancreatitis. The magnitude of response in both parameters differed significantly between patient groups. Reproduced with permission from reference 37

known complication of open heart surgery (20). In a recent prospective study multivariate analysis was used to identify the variables most strongly associated as risk factors for the development of acute pancreatitis after cardiac surgery (21).

Interestingly, one factor was perioperative administration of calcium chloride, which displayed a dose-related increase in risk. Although this close correlation cannot firmly establish a cause and effect relationship, causality is suggested by experimental studies demonstrating that acute hypercalcemia is sufficient to induce dose-dependent morphological alterations characteristic of acute pancreatitis, acute hyperamylasemia and early ectopic trypsinogen activation (22).

\section{NOVEL DIAGNOSTIC MARKERS}

Measurement of serum amylase levels is still the most common test used to confirm a diagnosis of acute pancreatitis. However, elevated serum total amylase is often associated with various nonpancreatic disorders. Hyperamylasemia often results from amylase of nonpancreatic origin, mainly salivary, or from decreased renal clearance (23). Better specificity has been described using urinary amylase-creatinine clearance or measuring serum isoamylase, lipase, trypsin(ogen), elastase or phospholipase A2 $(24,25)$.

The search for an ideal diagnostic marker has been intensive. An optimal tool should demonstrate better specificity, longer plasma peaks and improved correlation with clinical severity.

Recently several novel diagnostic markers have been investigated in animal experimental pancreatitis and in humans with acute pancreatitis. These include trypsinogen activation peptides, phospholipase A2 activation peptides, $\mathrm{C}$ reactive protein and the pancreatitis-associated protein $(26,27)$. Several inflammation markers also appear to serve as prognostic indexes, including the inflammatory cytokines interleukin (IL)-1, IL-6 (Figure 4) and tumour necrosis factor-alpha (28). Other promising markers, such as the zymogen granule membrane protein GP2, have not yet been studied in humans (29).

\section{FUTURE THERAPEUTIC TOOLS}

Although the treatment of pancreatitis is largely supportive, several attempts - directed mainly at finding therapeutic inhibitors of proteases and phospholipase - have been made to develop specific treatment. After the protease inhibitor aprotinin failed in clinical trials, other protease inhibitors such as gabexate mesilate, camostate and nafomostat mesilate were evaluated. Despite promising results in experimental animals, clinical trials in humans have yielded conflicting results (30).

Because intravenous protease inhibitors have failed to demonstrate efficacy, investigators have suggested an alternative approach based on recent experimental evidence that digestive enzymes can be activated within the acinar cell. In this process lysosomal enzymes are being colocalized with digestive zymogens which, in turn, activate trypsin in an acidic $\mathrm{pH}$ optimum. The amine chloroquine is a weak base that accumulates in several acidic intracellular organelles, including lysosomes, and is capable of increasing $\mathrm{pH}$. Although lysosomal acidity is a prerequisite for trypsinogen activation, and such therapy would be expected to ameliorate experimental pancreatitis, use of this drug has so far been disappointing (31). However, further research of other modes of therapy that are able to affect intracellular trypsin activation is indicated. The use of endogenous anti-inflammatory cytokines is another consideration for treating acute 
pancreatitis. IL-10 decreases the severity of murine experimental acute pancreatitis, mainly by inhibiting the development of acinar necrosis. Inhibition of local tumour necrosis factor-alpha might explain, at least in part, the protective effect of IL-10 (32).

The use of antioxidants and free radical scavengers in other types of experimental acute pancreatitis appear to have some potential for treatment (33). Further research using other more potent antioxidants may offer more effective therapy.

Nitrous oxide modulates pancreatic secretion and maintains pancreatic bloodflow by regulating vascular tone. Because acute pancreatitis is associated with impaired vascular function, the role of nitrous oxide and some nitrous oxide

\section{REFERENCES}

1. Miller TL, Winter HS, Luginbuhl LM, Orav EJ, McIntosh K. Pancreatitis in pediatric human immunodeficiency virus infection. J Pediatr 1992;120:223-7.

2. Butler KM, Venzon D, Henry N, et al. Pancreatitis in HIV-infected children receiving dideoxyinosine. Pediatrics 1993;91:747-51.

3. Kahler SG, Sherwood G, Woolf D, et al. Pancreatitis in patients with organic acidemias. J Pediatr 1994;124:239-43.

4. Werlin SL, Casper J, Antonson D, Calabro C. Pancreatitis associated with bone marrow transplantation in children. Bone Marrow Transplant 1992;10:65-9.

5. Druml W, Laggner AN, Lenz K, Grimm G, Schneeweib B. Pancreatitis in acute hemolysis. Ann Hematol 1991;63:39-41.

6. Dougherty FE, Ernst SG, Aprille JR. Familial recurrence of atypical symptoms in an extended pedigree with the syndrome of mitochondrial encephalomyopathy, lactic acidosis and strokelike episodes (MELAS). J Pediatr 1994;125:758-61.

7. Heitlinger LA, McClung HJ, Murray RD, Li BUK. Recurrent pancreatitis in three patients with chronic idiopathic intestinal pseudo-obstruction. J Pediatr Gastroenterol Nutr 1991;13:92-5.

8. Steinberg W, Tenner S. Acute pancreatitis. N Engl J Med 1994;330:1198-210.

9. Steer ML, Meldolesi J. The cell biology of experimental pancreatitis. N Engl J Med 1987;316:144-50.

10. Lankisch PG, Muller CH, Niederstadt $\mathrm{H}$, et al. Painless acute pancreatitis subsequent to anticholinesterase insecticide intoxication. Am J Gastroenterol 1990;85:872-5.

11. Liu S, Oguchi Y, Borner JW, et al. Increased canine pancreatic acinar cell damage after organophosphate and acetylcholine or cholecystokinin. Pancreas 1990;5:177-82.

12. Weizman Z, Sofer S. Acute pancreatitis in children with anticholinesterase insecticide intoxication. Pediatrics 1992;90:204-6.

13. Bartholomew C, McGeeney KP, Murphy JJ, et al. Experimental studies on the etiology of acute scorpion pancreatitis. Br J Surg 1976;63:807-10.

14. Sofer S, Shalev H, Weizman Z, et al. Acute pancreatitis in children following envenomation by the yellow scorpion Leiurus quinquestriatus. Toxicon 1991;29:125-8.

15. Gallagher S, Sankaran H, Williams JA. Mechanism of scorpion toxin-induced enzyme secretion in rat pancreas. Gastoenterology 1981;80:970-3.

16. Niederau C, Ude K, Niederau M, et al. Effects of the seleno-organic substance ebselen in two different models of acute pancreatitis. Pancreas 1991;6:282-90.

17. Neuschwander-Tetri BA, Ferrell LD, Sukhabote RJ, Grendell JH. Glutathione monoethyl ester ameliorates cerulein-induced pancreatitis in the mouse. J Clin Invest 1992;89:109-16.

18. Villarreal HA, Wells LD, Neuschwander-Tetri BA. Azathioprine depletes pancreatic glutathione and induces gamma-glutmylcysteine synthetase activity. Gastroenterology 1995;108:398A. (Abst)

19. Kim YT, Yoon YB, Kim CY. Effect of alpha-tocopherol in cerulein-induced acute pancreatitis in mice. Gastroenterology 1995;108:365A. (Abst) donor drugs have been studied in experimental acute pancreatitis with promising initial results (34).

\section{CONCLUSIONS}

The aim of the present review was to illustrate the crucial importance of our fundamental understanding of the pathogenesis of acute pancreatitis in order to develop insight into improved methods of treating or preventing this serious condition. Thorough investigation of pathogenetic mechanisms will improve awareness and understanding of pancreatic involvement in a variety of pediatric disorders. It will also enable the prevention of damage by drugs and toxins and permit the development of better clinical diagnostic and therapeutic tools.

20. Leijala M, Louhimo I. Pancreatitis after open heart surgery in children. Eur J Cardiothorac Surg 1988;2:324-8.

21. Fernandez-del-Castillo C, Harringer W, Warshaw AL, et al. Risk factors for pancreatic cellular injury after cardiopulmonary bypass. N Engl J Med 1991;325:382-7.

22. Mithofer K, Fernandez-del-Castillo C, Frick TW, et al. Acute hypercalcemia causes acute pancreatitis and ectopic trypsinogen activation in the rat. Gastroenterology 1995;109:239-46.

23. Pieper-Bigelow C, Strocchi A, Levitt MD. Where does serum amylase come from and where does it go? Gastroenterol Clin North Am 1990;19:793-810.

24. Weizman Z, Durie PR. Acute pancreatitis in childhood. J Pediatr 1988;113:24-9.

25. Weizman Z. Acute pancreatitis. In: Wyllie R, Hyams JS, eds. Pediatric Gastrointestinal Disease Textbook, 1st edn. Philadelphia: WB Saunders Company, 1993:873-9.

26. Schmidt J, Fernandez-del-Castillo C, Rattner DW, et al. Trypsinogen-activation peptides in experimental rat pancreatitis: prognostic implications and histopathologic correlates. Gastroenterology 1992;103:1009-16.

27. Iovanna JL, Keim V, Nordback I, et al. Serum levels of pancreatitis-associated protein as indicators of the course of acute pancreatitis. Gastroenterology 1994;106:728-34.

28. Leser HG, Gross V, Scheibenbogen C, et al. Elevation of serum interleukin- 6 concentration precedes acute-phase response and reflects severity in acute pancreatitis. Gastroenterology 1991;101:782-5.

29. Lowe AW, Luthen RE, Wong SM, Grendell JH. The level of the zymogen granule protein GP2 is elevated in a rat model for acute pancreatitis. Gastroenterology 1994;107:1819-27.

30. Warshaw AL. Damage prevention versus damage control in acute pancreatitis. Gastroenterology 1993;104:1216-9.

31. Lerch ML, Saluja AK, Dawra R, Saluja M, Steer ML. The effect of chloroquine administration on two experimental models of acute pancreatitis. Gastroenterology 1993;104:1768-79.

32. Van Laethem JL, Marchant A, Delvaux A, et al. Interleukin-10 prevents necrosis in murine experimental acute pancreatitis. Gastroenterology 1995;108:1917-22.

33. Niederau C, Niederau M, Borchard F, et al. Effects of antioxidants and free radical scavengers in three different models of acute pancreatitis. Pancreas 1992;7:486-96.

34. Molero X, Guarner F, Salas A, Mourelle M, Puig V, Malagelada JR. Nitric oxide modulates pancreatic basal secretion and response to cerulein in the rat: effects in acute pancreatitis. Gastroenterology 1995;108:1855-62.

35. Steer ML, Meldolesi J, Figarella C. Pancreatitis; the role of lysosomes. Dig Dis Sc 1984;29:934-8.

36. Luthen RE, Grendell JH. Thiol metabolism and acute pancreatitis: trying to make the piece fit. Gastroenterology 1994;107:888-92.

37. Heath DI, Cruickshank A, Gudgeon AM, Jehanli A, Shenkin A, Imrie $\mathrm{CW}$. The relationship between pancreatic enzyme release and activation and the acute-phase protein response in patients with acute pancreatitis. Pancreas 1995;10:347-53. 


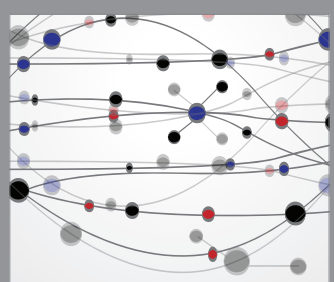

The Scientific World Journal
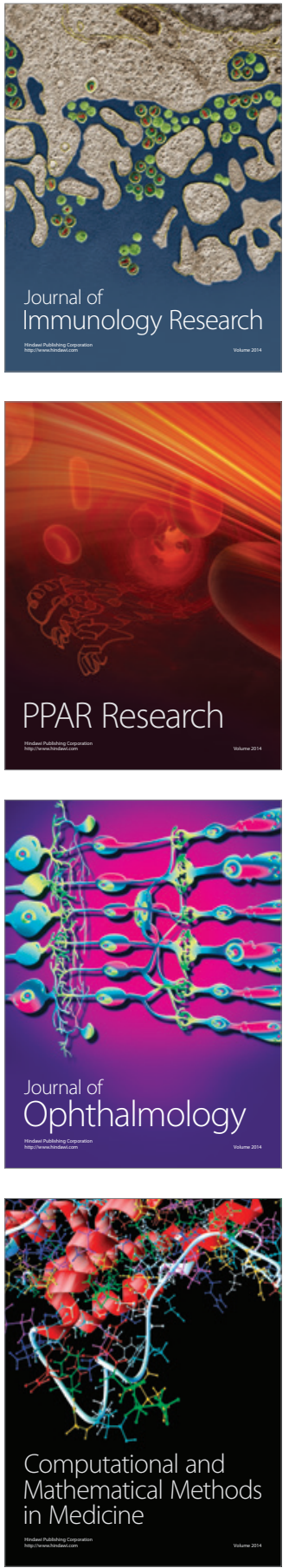

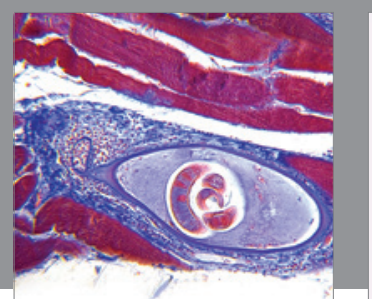

Gastroenterology Research and Practice

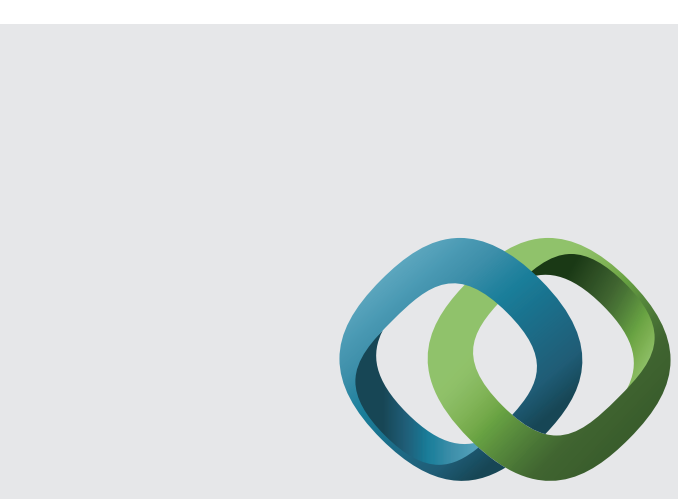

\section{Hindawi}

Submit your manuscripts at

http://www.hindawi.com
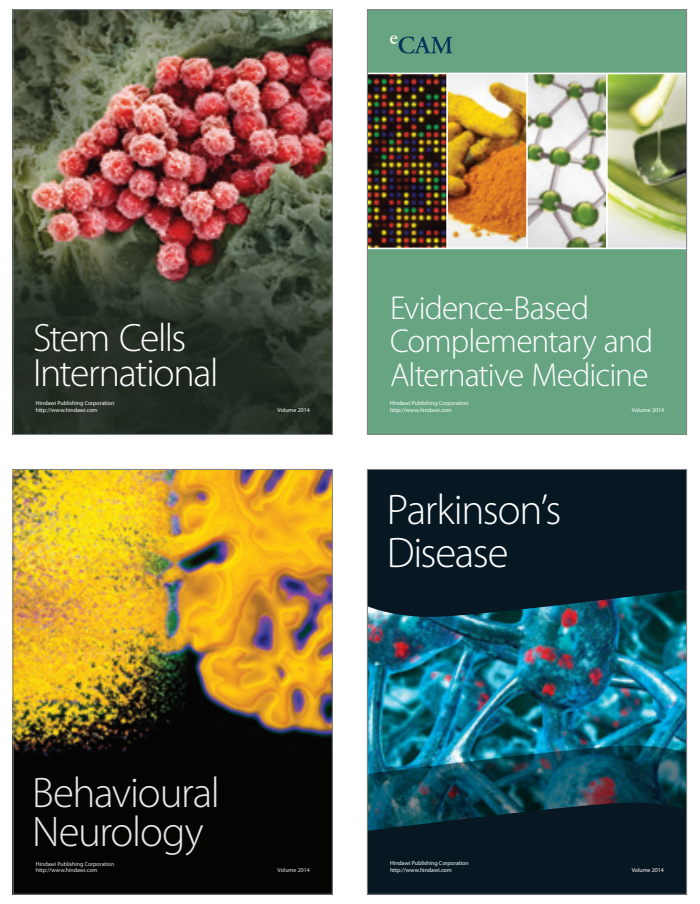
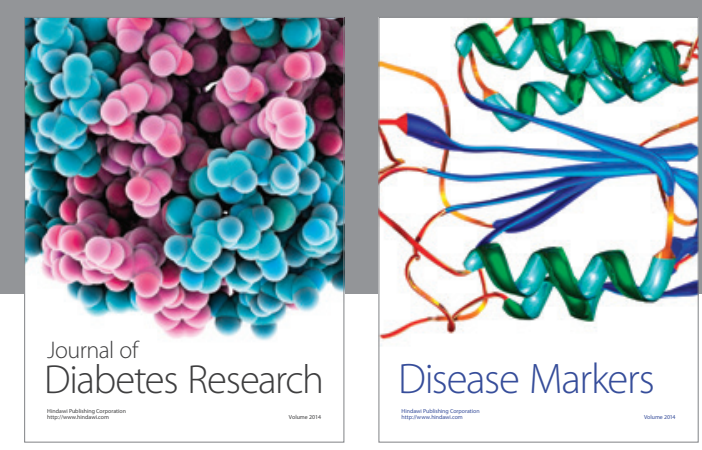

Disease Markers
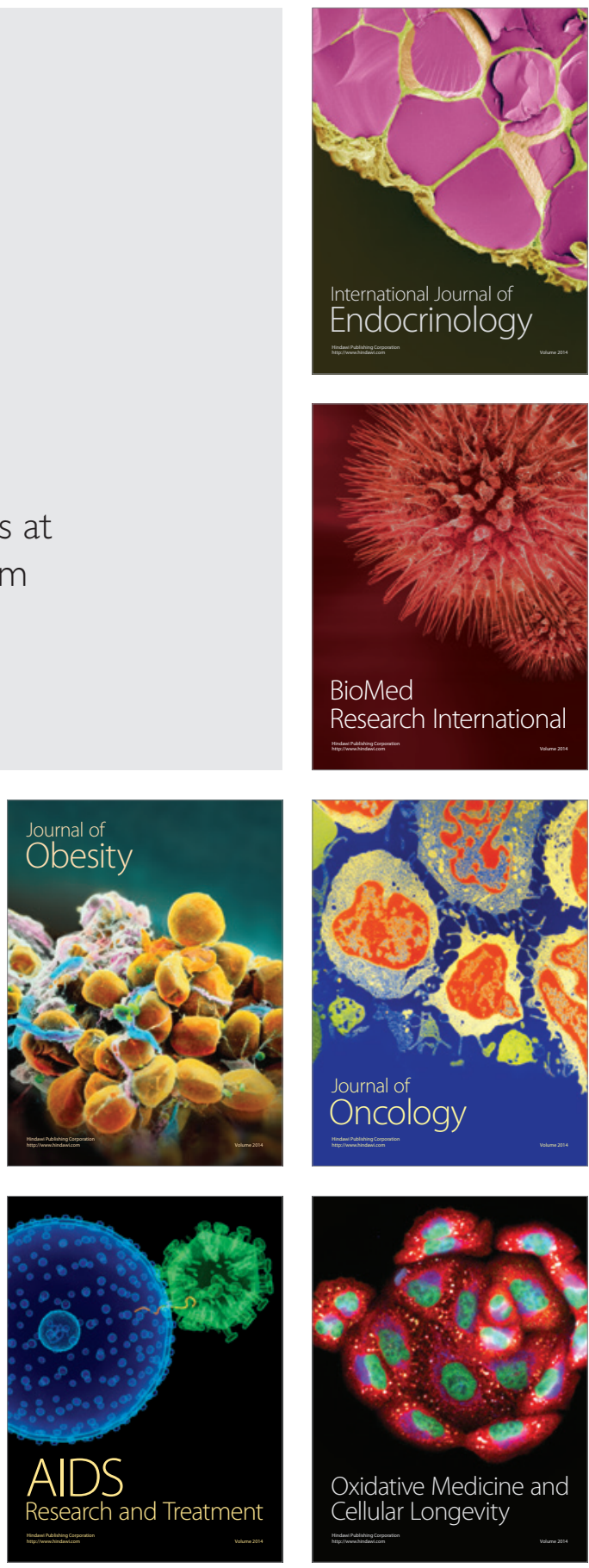